\title{
UWB Antenna with All Band Suitable Radiation Pattern for Breast Cancer Detection
}

\author{
T. G. Abouelnaga ${ }^{\# 1}$, A. F. Desouky ${ }^{* 2}$ \\ ${ }^{\#}$ Researcher, Microstrip Circuits Department, Electronics Research Institute, Giza, Egypt \\ \# Assistant Professor, Communication Department, \\ Higher Institute of Engineering and Technology, Kafr El-Shiekh, Egypt \\ ${ }^{1}$ tamer@eri.sci.eg \\ * Teacher Assistant, Communication Department, Higher Institute of Engineering and Technology, Kafr El- \\ Shiekh, Egypt \\ 2asmaa.fereg@gmail.com
}

\begin{abstract}
In this paper, design and implementation of two ultra-wideband balanced antipodal Vivaldi antennas for breast cancer detection are introduced. The antennas bandwidth extend from $2.6 \mathrm{GHz}$ to 11.6 GHz. The problem arises from the unsuitable radiation pattern at the lower band of frequencies. This problem is solved by adding rectangular slits at the antenna's edge. The slits' dimensions are optimized using CST simulator and their effects are demonstrated. Also, two breast phantoms with and without tumor are proposed for breast tumors detection. The phantom's dielectric constant are relatively close to the real breast tissues and real tumors. The dispersive characteristics of the phantoms' material are considered. The fields' distribution inside the phantom with and without tumor are investigated. Low cost FR4 material is considered as an antenna substrate. The proposed antennas are fabricated and measured. Good agreement is obtained between simulated and measured results.
\end{abstract}

Keyword-Vivaldi Antenna, Ultra Wide Band, Radiation Pattern, Broad-side, End-fire

\section{INTRODUCTION}

Breast cancer, particularly in women has become the most common disease. Effective treatment is mainly based on early detection. X-ray mammogram and other medical images methods are common methods for breast cancer detection. These methods use ionizing radiation and they require uncomfortable breast compression during examination. Medical imaging methods other than X-ray have been applied for breast imaging. Magnetic resonance imaging (MRI) is a very useful detection method. However, it is expensive [1]. Microwave detection of breast tumors is an attractive method because the ionizing radiation and the breast compression are avoided and indeed it is considered a potentially low-cost alternative [2]. In microwave detection process, the high difference between the dielectric properties of a malignant tumor and the normal breast tissue is used to explore tumors $[3,4]$. The ultra-wide band signals provides ultra-wide band reflections, high resolution, fast image reconstruction and robust signal processing [1]. Many researches have been introduced different UWB antenna structures. R. Nilavalan and et al had discussed a wideband microstrip antenna for breast cancer tumor detection. The bandwidth extended from $4 \mathrm{GHz}$ to $9.5 \mathrm{GHz}$ [2]. An UWB aperture stacked patch antenna were proposed by Klemm and et al for breast cancer detection radar system. A successful detection of 4 and $6 \mathrm{~mm}$ diameters spherical tumors had demonstrated [5]. Gibbins and et al had discussed a comparison of two ultra-wide band antennas and successes in using smaller antenna with fidelity more than 95\% [6]. Bourqui and et al had introduced a balanced antipodal Vivaldi antenna with dielectric director to improve gain and directivity for near field microwave imaging [7]. Al-Joumayly and et al had introduced a dual band miniaturized antenna for microwave breast imaging [8]. Xuyang Li and et al had discussed a compact double layer of bowtie antenna which characterized from 0.5 to $2 \mathrm{GHz}$ [9]. Mamadou and et al had discussed a Vivaldi antenna operated from 3.1 to $10.6 \mathrm{GHz}$ and had introduced a breast phantom with dielectric properties close to normal breast [10]. Jalilvand and et al had discussed an ultra-wide band bowtie antenna operated in the range of 1.2-7 GHz with small size, hemispherical array of 16 compact bowtie antennas. A breast phantom of two layer for three dimensional detection of breast tumor had been successfully implemented [11]. H. Bahrami and et al had discussed a flexible ultra-wide band antenna operated in the range of $2-4 \mathrm{GHz}$ and a flexible sixteen antenna array for microwave breast cancer detection [12]. Table1 shows a comparison among different antennas which had been used in microwave detection system. This paper presents an ultra-wide band balanced antipodal Vivaldi antenna design which operates in the frequency range of $2.8 \mathrm{GHz}$ to $11.6 \mathrm{GHz}$. The proposed antenna has a suitable radiation pattern all over the entire UWB. Also, a breast phantom of two layers (tissue and tumor) with electrical properties which are very close to the real breast are introduced. The proposed antennas are simulated considering the presence of breast phantom with and without 
tumor. The field distribution inside the breast phantom is discussed. The proposed antennas are fabricated, measured and the obtained results are discussed.

TABLE I. Different Antennas for Microwave Detection System

\begin{tabular}{|l|l|l|}
\hline Reference & Antenna Size & Bandwidth \\
\hline$[2]$ & $9 \times 6.5 \mathrm{~mm}^{2}$ & $4-9 \mathrm{GHz}$ \\
\hline$[5]$ & $23 \times 29 \mathrm{~mm}^{2}$ & $4.5-10 \mathrm{GHz}$ \\
\hline$[6]$ & $13 \times 14 \mathrm{~mm}^{2}$ & $4.5-10 \mathrm{GHz}$ \\
\hline$[7]$ & $44 \times 74 \mathrm{~mm}^{2}$ & $2.4-18 \mathrm{GHz}$ \\
\hline$[8]$ & $29 \times 28 \mathrm{~mm}^{2}$ & $0.5-3 \mathrm{GHz}$ \\
\hline$[9]$ & $30 \times 30 \mathrm{~mm}^{2}$ & $0.5-2 \mathrm{GHz}$ \\
\hline$[10]$ & $42.95 \times 42.95 \mathrm{~mm}^{2}$ & $3.1-10.6 \mathrm{GHz}$ \\
\hline$[11]$ & $15 \times 15 \mathrm{~mm}^{2}$ & $1.2-7 \mathrm{GHz}$ \\
\hline$[12]$ & $20 \times 20 \mathrm{~mm}^{2}$ & $2-4 \mathrm{GHz}$ \\
\hline
\end{tabular}

\section{CONVENTIONAL ANTENNA DESIGN}

The conventional antenna is designed based on [13]. Fig.1. shows the antenna structure. FR-4 material has been considered as antenna substrate with dielectric constant of 4.65 and height of $1.27 \mathrm{~mm}$. Given the lowest frequency $\left(f_{l}\right)$, substrate thickness (h) and dielectric constant $\mathcal{E}_{r}$. The width (W) and length (L) of the antenna can be calculated using the following equation

$$
W=L=\frac{C}{f_{l}} \sqrt{\frac{2}{\varepsilon_{r}+1}}
$$

Where $\mathrm{c}$ is the speed of light in free space. The antenna structure is formed from the intersection of quarters of two ellipses. The major radii $\left(r_{1}\right.$ and $\left.r_{2}\right)$ and the minor radii $\left(r_{s 1}\right.$ and $\left.r_{s 2}\right)$ of the two ellipses as shown in Fig. 1. The two ellipses are chosen according to the following equations [14]

$$
\begin{gathered}
r_{1}=\frac{W}{2}+\frac{W_{1}}{2}, \\
r_{2}=\frac{W}{2}-\frac{W_{1}}{2}, \\
r_{s 1}=L, \\
r_{s 2}=0.5 r_{2} .
\end{gathered}
$$

The width of the microstrip transmission feeder $W_{1}$ for a characteristic impedance, $Z_{o}=50 \Omega$, can be calculated using the following equations [15].

$$
\begin{gathered}
Z_{o}=\frac{60}{\sqrt{\mathcal{E}_{\text {reff }}}}\left[\frac{8 h}{W_{1}}+\frac{W_{1}}{4 h}\right], \quad W_{1} / h \leq 1 \\
Z_{o}=\frac{120 \pi}{\sqrt{\varepsilon_{\text {reff }}}\left[\frac{W_{1}}{h}+1.393+0.667 \ln \left(\frac{W_{1}}{h}+1.444\right)\right]}, \quad W_{1} / h>1
\end{gathered}
$$

Where the effective dielectric constant for the transmission line, $\mathcal{E}_{\text {reff }}$ is given by

$$
\varepsilon_{\text {reff }}=\frac{\mathcal{E}_{r}+1}{2}+\frac{\mathcal{E}_{r}-1}{2}
$$

Figure 2 shows the return loss of the conventional antenna and it's noticed that this antenna suffers from mismatch at lower frequency band which extends from $3 \mathrm{GHz}$ to $9.5 \mathrm{GHz}$. The conventional antipodal Vivaldi antenna doesn't cover the UWB. To improve the performance, conventional antipodal Vivaldi antenna is modified. Conventional antenna feeding line is modified to improve the characteristic impedance of the antenna [16]. 


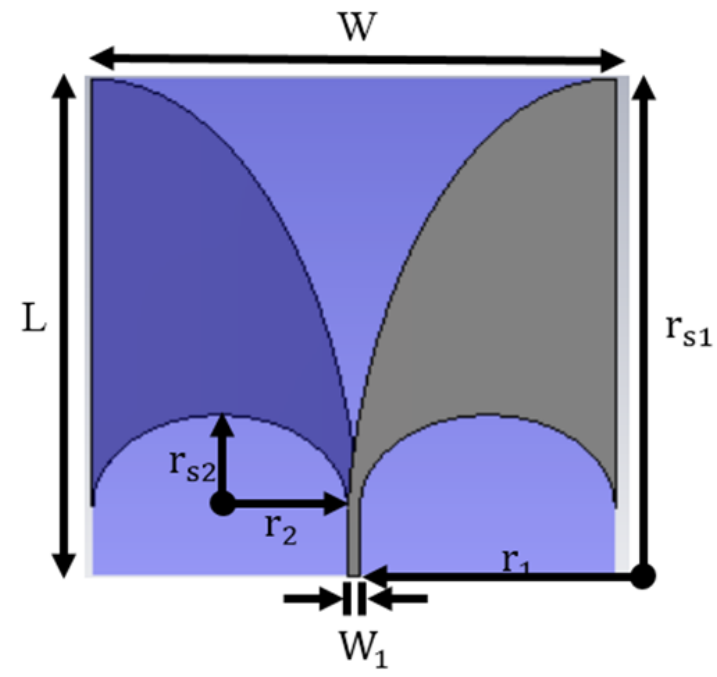

Fig.1 Conventional Vivaldi antenna

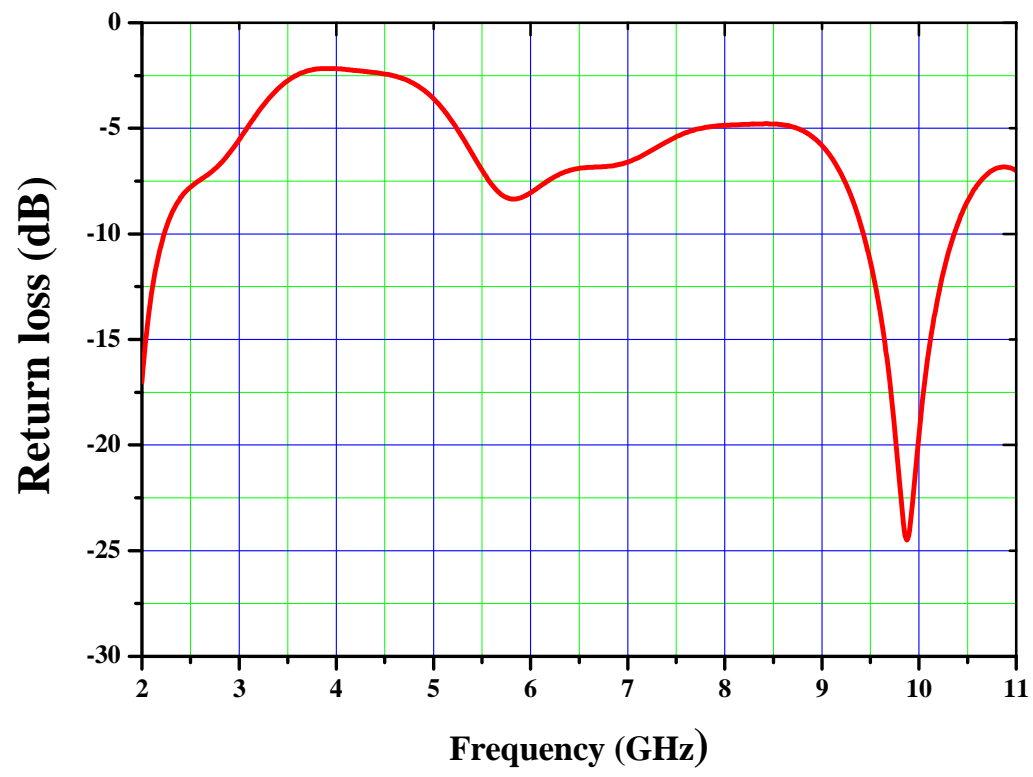

Fig. 2 Simulated return loss of the conventional antenna

\section{A. Antipodal Vivaldi Antenna With Modified Feed Line}

Figure 3 shows the simulated proposed antipodal Vivaldi antenna with modified feed line using CST Microwave Studio 2014. Figure 4 shows the simulated return loss. The modified feed antipodal Vivaldi antenna (AVA) operates in the frequency range 3.1-11.6 GHz. Figure 5 shows the radiation patterns at different low frequencies. It has been noticed that the main beam direction at low frequencies changed from the end fire direction to a broad side direction. This, indeed make the antenna radiation deviate from the end-fire direction which is required all over the entire band. This is the major disadvantage of this structure. 


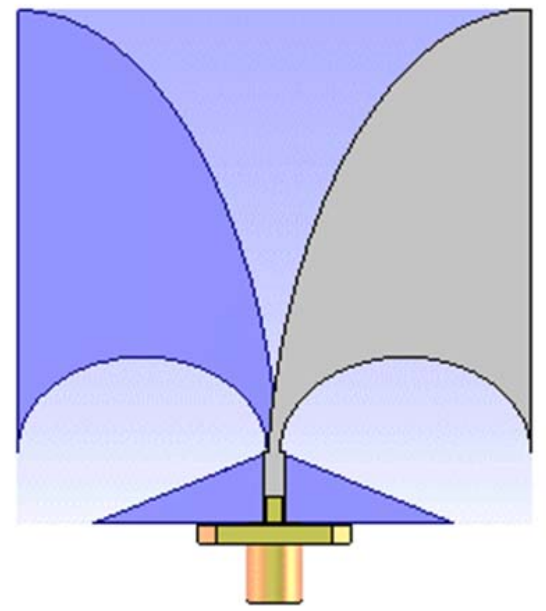

Fig.3 Antipodal Vivaldi antenna

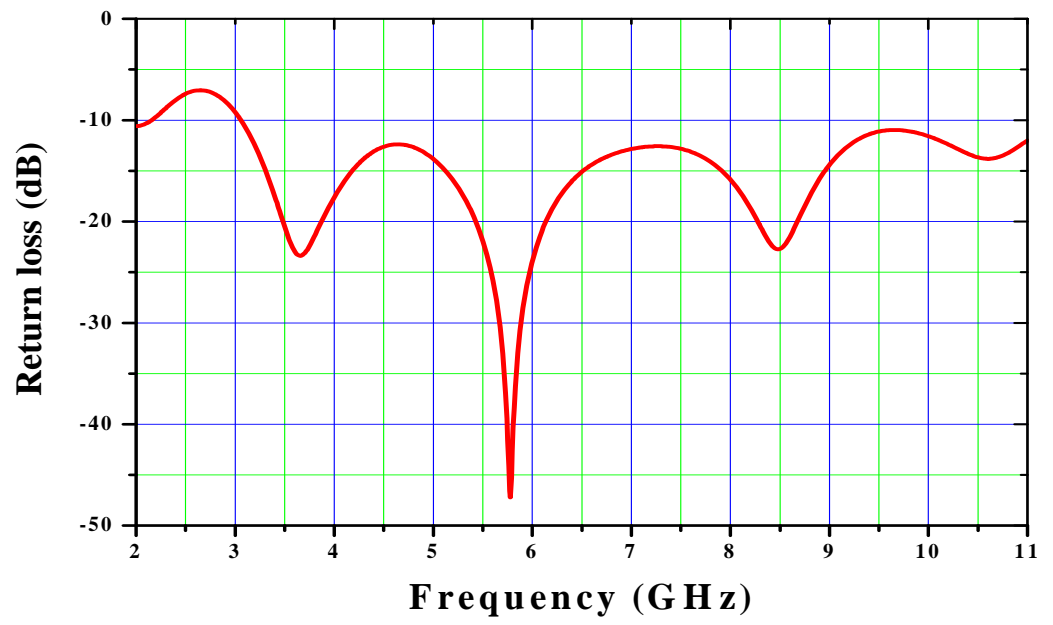

Fig. 4 Simulated return loss of the antipodal modified feed Vivaldi antenna

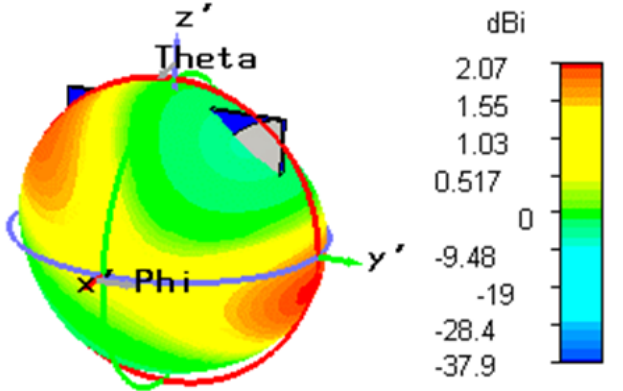

(a)

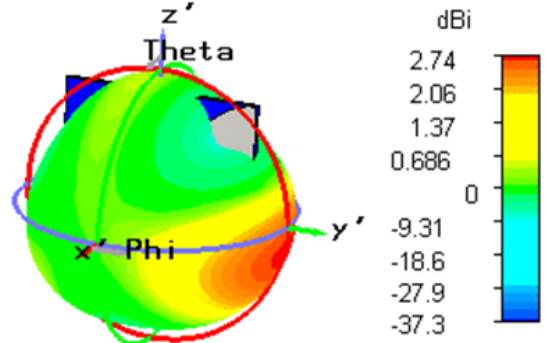

(c)

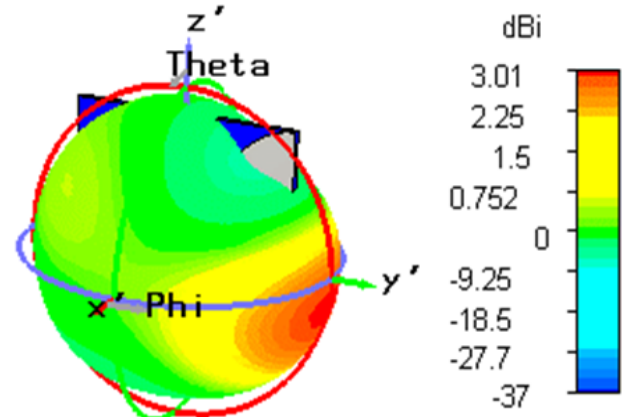

(b)

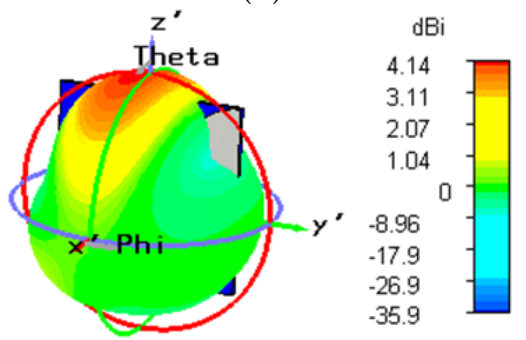

(d)

Fig. 5Antipodal modified feed Vivaldi antenna simulated radiation pattern at (a) $3.1 \mathrm{GHz}$, (b) $3.2 \mathrm{GHz}$, (c) $3.5 \mathrm{GHz}$ and(d) $4 \mathrm{GHz}$ 
From the previous two sections, one can notice that the radiation pattern direction is a broadside at low frequencies and at $4 \mathrm{GHz}$ and higher frequencies, the radiation pattern is an end-fire. This problem is solved in the next two proposed structures of antipodal Vivaldi antenna by adding slits in the radiating structure to transfer the radiation direction from broad side to end fire direction.

\section{B. Antipodal Vivaldi Antenna With Slits}

Figure 6 shows the proposed antipodal Vivaldi antenna with rectangular slits which are added to the antenna's outer edge. CST Microwave Studio 2014 is used to optimize the slits dimensions. Table 2 shows the antenna's optimized dimensions. Figure 7 shows the simulated return loss of the conventional and proposed antipodal Vivaldi antenna with rectangular slits. One can notice that an enhancement of about $10 \mathrm{~dB}$ is obtained. The proposed antenna operates in the frequency range 2.6-11 GHz. The proposed antenna is fabricated using FR4 material with dielectric constant $\mathcal{E}_{r}=4.65$, height of $1.5 \mathrm{~mm}$ and loss tangent $\tan \delta=0.025$, Fig. 8 . Figure 9 shows the measured return loss of the proposed antenna which agrees well with the simulated one. Figure 10 shows the radiation pattern direction of the proposed antipodal Vivaldi antenna with slits at lower frequency band. It can be noticed that the obtained radiation pattern are end-fire and in the same direction as all higher frequencies.

TABLE II. Proposed Antenna Parameter Values in mm

\begin{tabular}{|l|l|l|l|l|l|l|l|l|l|l|}
\hline W & W1 & W2 & W3 & W4 & W5 & L & L1 & L2 & L3 & L4 \\
\hline 42.85 & 5 & 7 & 5 & 1.8 & 30 & 42.85 & 17 & 7 & 14 & 3 \\
\hline
\end{tabular}

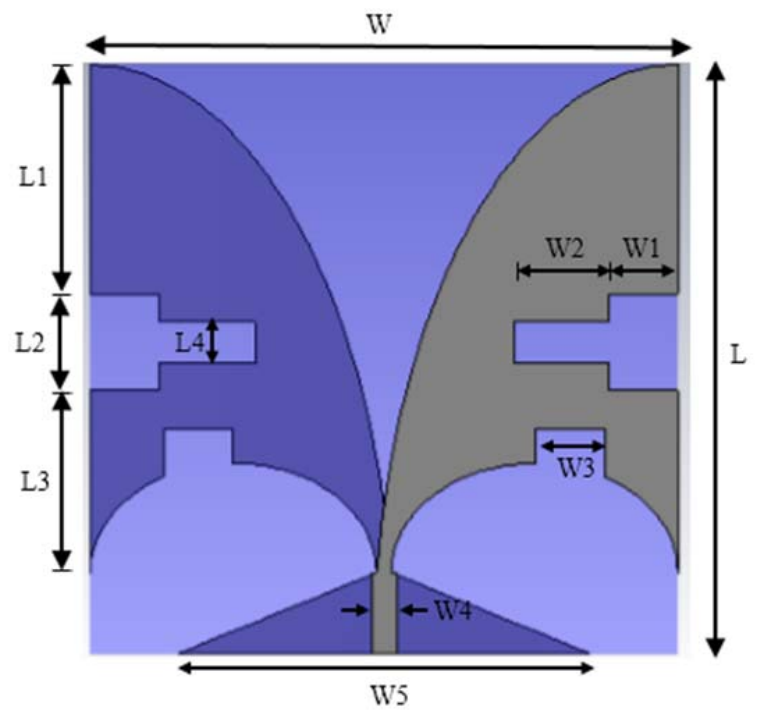

Fig.6 Proposed antenna parameter

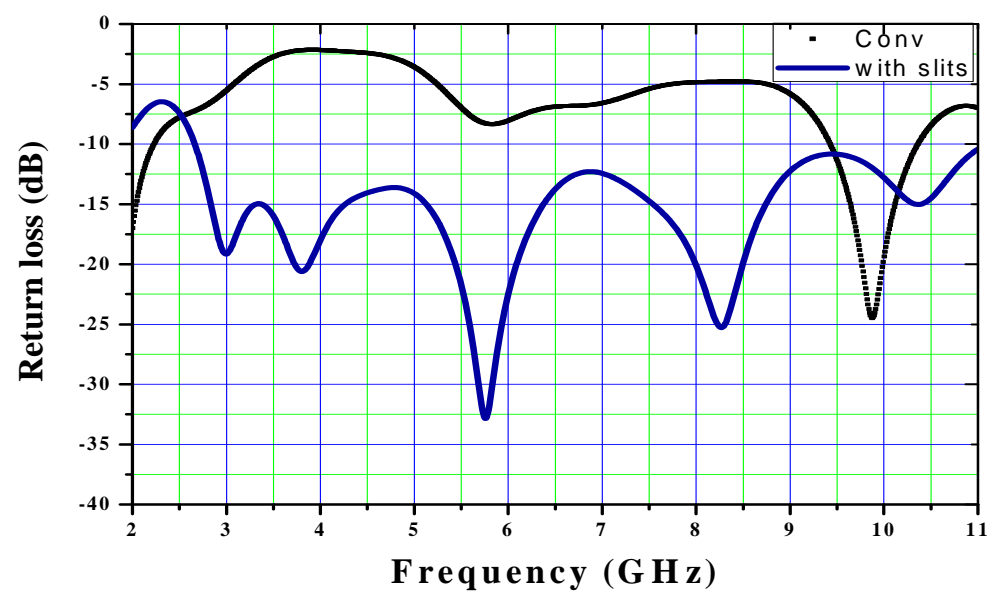

Fig. 7 Simulated return loss of antipodal Vivaldi antenna with slits and conventional antenna 


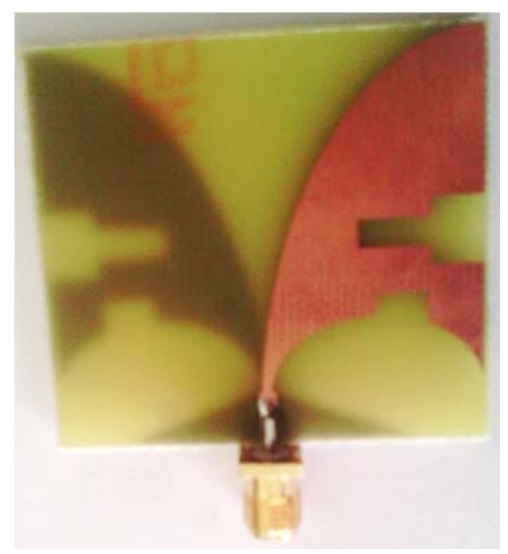

Fig.8 Fabricated photo of the proposed antipodal Vivaldi antenna with slits

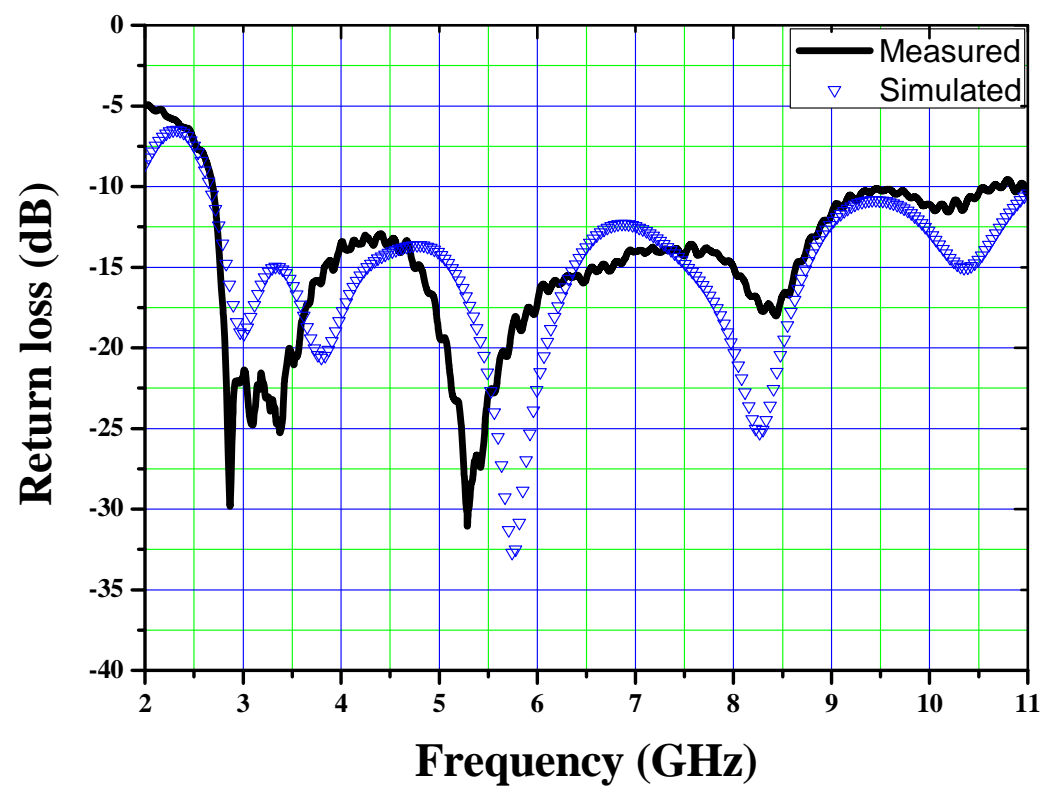

Fig. 9 Measured and simulated return loss of the proposed antipodal Vivaldi antenna with slits

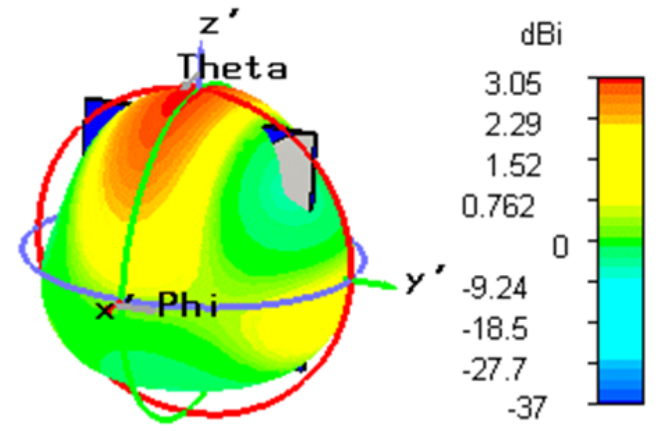

(a)

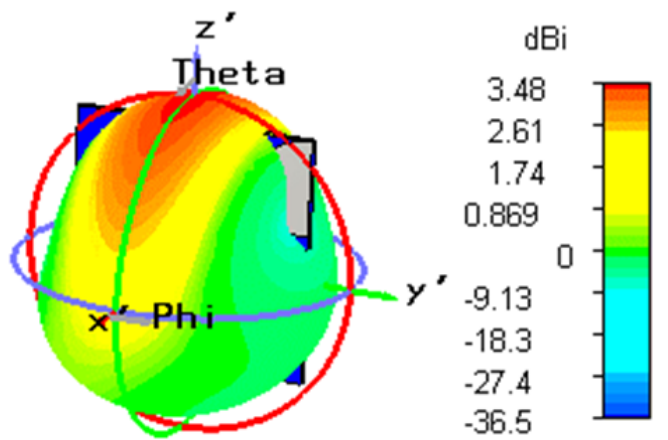

(b) 


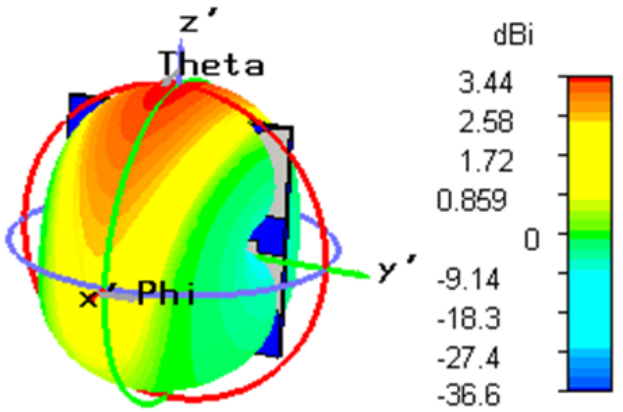

(c)

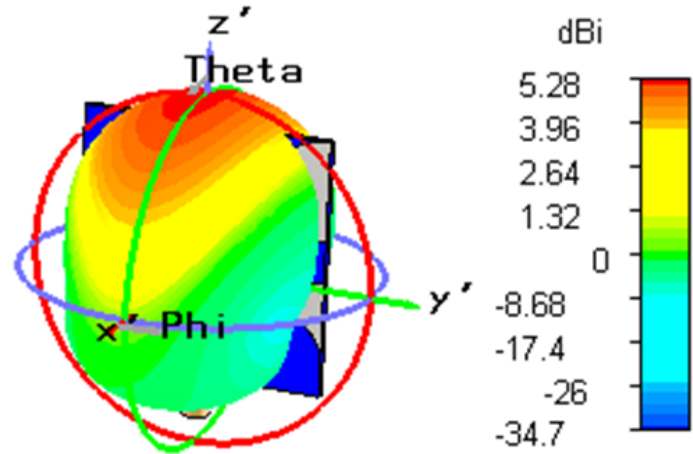

(d)

Fig. 10 Simulated radiation pattern of the proposed antipodal Vivaldi antenna with slits. (a) $3 \mathrm{GHz}$, (b) $3.2 \mathrm{GHz}$, (c) $3.5 \mathrm{GHz}$ and (d) 4 GHz.

\section{Antipodal Vivaldi Antenna With Slits and Meandered Edge}

In this structure the antenna edge is meandered, Fig.11. This meandering enhances the matching better than the previous structure as shown in Fig.12. Matching enhancement of about $5 \mathrm{~dB}$ at $7.5 \mathrm{GHz}, 3 \mathrm{~dB}$ at $5 \mathrm{GHz}$ and about $5 \mathrm{~dB}$ at $4 \mathrm{GHz}$ are obtained. The proposed structure is fabricated using FR-4 material as substrate, Fig. 13 . Figure 14 shows both simulated and measured return loss of the proposed structure. Also, good agreement is obtained. Figure 15 shows that the radiation pattern direction is end- fire and in the same direction as all higher frequencies. So, the last two structures where rectangular slits are added, successfully solve the broad-side radiation problem that appears from the first structure at lower frequencies.

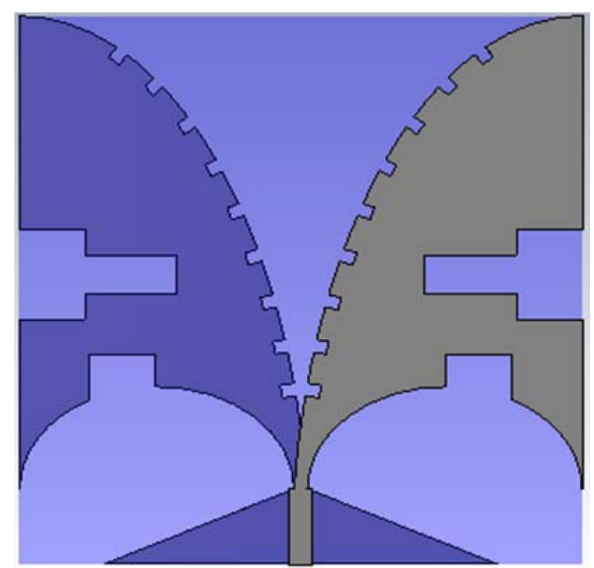

Fig.11 Proposed antipodal meandered Vivaldi antenna with slits

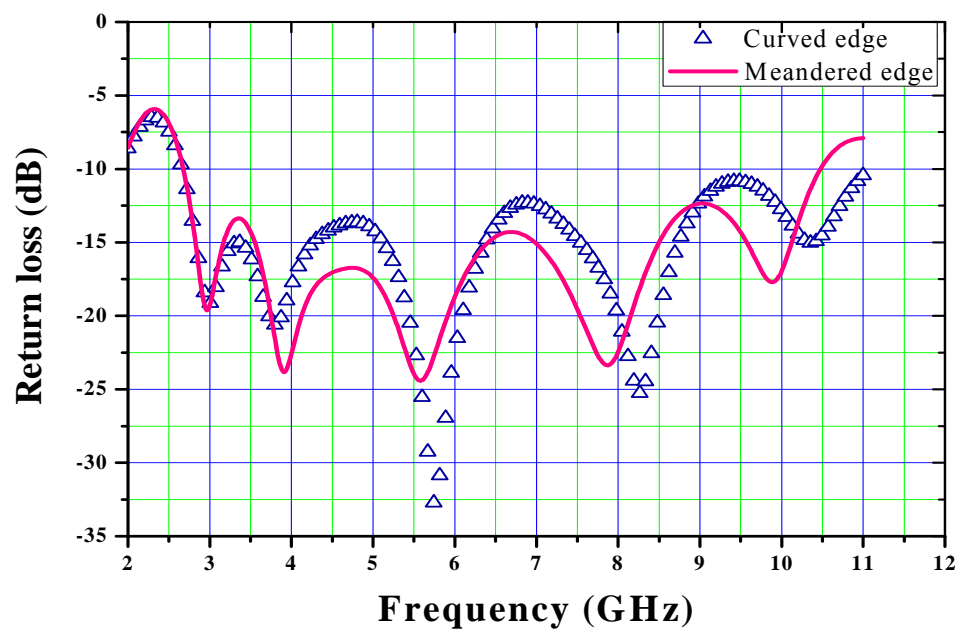

Fig. 12 Simulated return loss of the proposed antipodal Vivaldi antenna with slits and with and without meandered edge 


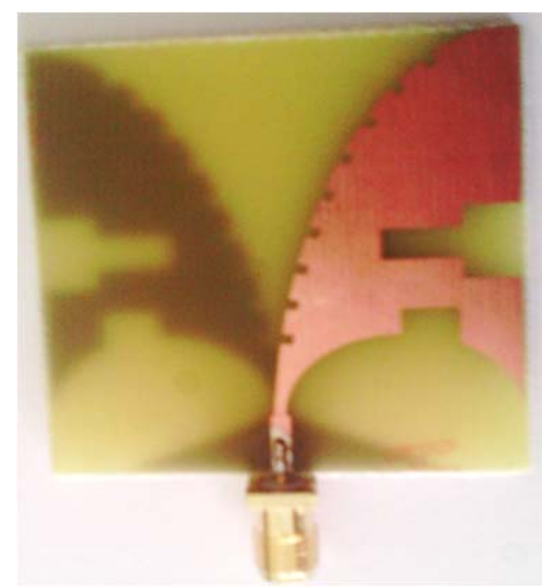

Fig.13 Fabricated proposed meandered edge antipodal Vivaldi antenna with slits.

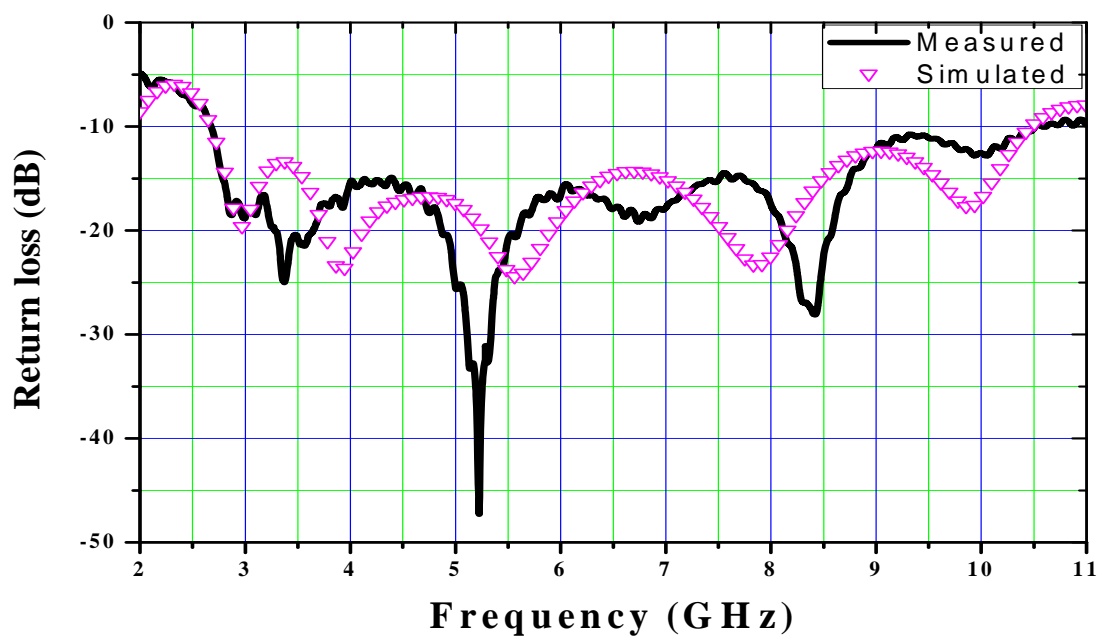

Fig. 14 Measured and simulated return loss of meandered edge antipodal Vivaldi antenna with slits

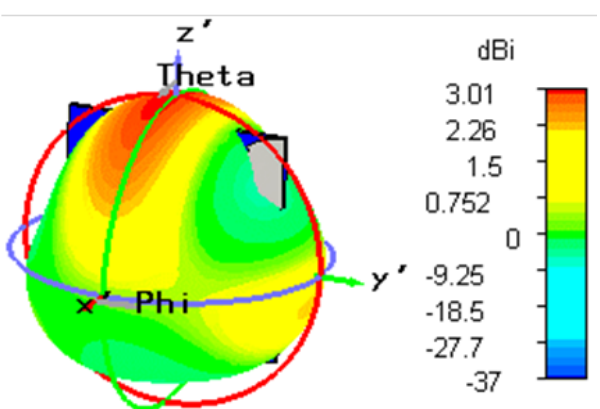

(a)

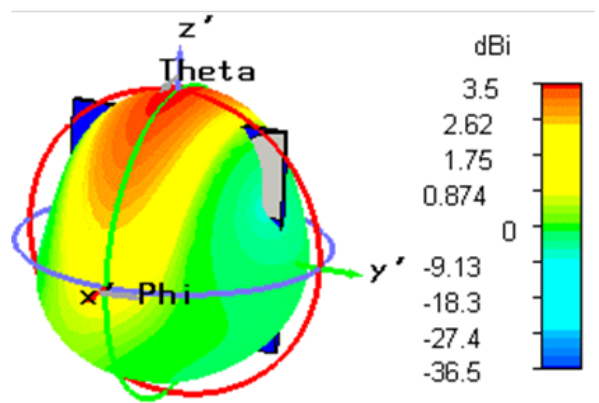

(b) 


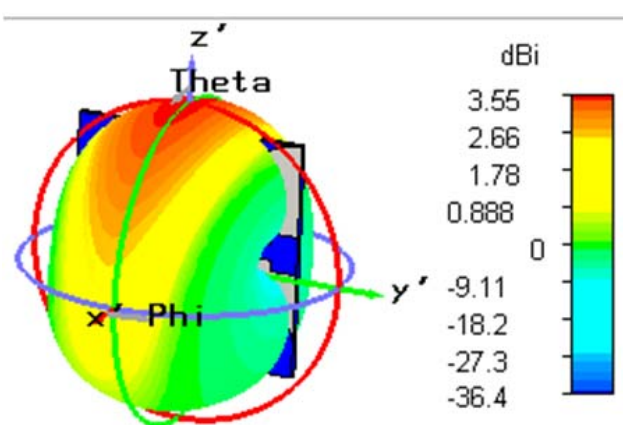

(c)

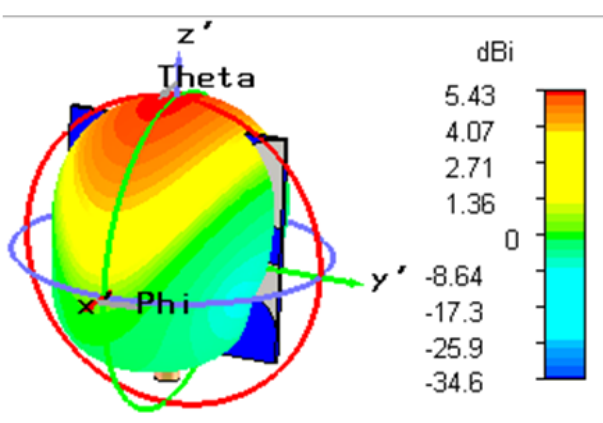

(d)

Fig. 15 Simulated radiation pattern direction of the structure. a) $3 \mathrm{GHz}$, b) $3.2 \mathrm{GHz}$, c) $3.5 \mathrm{GHz}$ and d) $4 \mathrm{GHz}$

Table 3, shows a comparison of the proposed structures from the bandwidth, main beam direction, gain, and directivity point of view.

TABLE III. Comparison of Different Proposed Antipodal Structures

\begin{tabular}{|c|c|c|c|c|c|}
\hline Structure & Frequency & $\begin{array}{l}\text { Main beam } \\
\text { direction }\end{array}$ & Gain & Directivity & BW \\
\hline \multirow{16}{*}{$\begin{array}{l}\text { Conventional antipodal } \\
\text { Vivaldi antenna with } \\
\text { modified feed line }\end{array}$} & $3.1 \mathrm{GHz}$ & Broadside & 1.517 & 1.610 & \multirow{16}{*}{$\begin{array}{l}3.1-11 \\
\mathrm{GHz}\end{array}$} \\
\hline & $3.2 \mathrm{GHz}$ & Broadside & 1.848 & 1.998 & \\
\hline & $3.5 \mathrm{GHz}$ & Broadside & 1.760 & 1.881 & \\
\hline & $4 \mathrm{GHz}$ & End fire & 2.427 & 2.595 & \\
\hline & $4.5 \mathrm{GHz}$ & End fire & 3.564 & 3.858 & \\
\hline & $4.9 \mathrm{GHz}$ & End fire & 3792 & 4.141 & \\
\hline & $5 \mathrm{GHz}$ & End fire & 3.803 & 4.163 & \\
\hline & $5.5 \mathrm{GHz}$ & End fire & 3.900 & 4.279 & \\
\hline & $5.7 \mathrm{GHz}$ & End fire & 3.944 & 4.342 & \\
\hline & $6 \mathrm{GHz}$ & End fire & 3.972 & 4.410 & \\
\hline & $6.5 \mathrm{GHz}$ & End fire & 3.972 & 4.448 & \\
\hline & $7 \mathrm{GHz}$ & End fire & 4.103 & 4.658 & \\
\hline & $7.5 \mathrm{GHz}$ & End fire & 4.831 & 5.523 & \\
\hline & $8 \mathrm{GHz}$ & End fire & 5.666 & 6.565 & \\
\hline & $8.5 \mathrm{GHz}$ & End fire & 6.143 & 7.183 & \\
\hline & $9 \mathrm{GHz}$ & End fire & 6.222 & 7.401 & \\
\hline \multirow{17}{*}{$\begin{array}{l}\text { Proposed antipodal Vivaldi } \\
\text { antenna with slits and without } \\
\text { meandered edge }\end{array}$} & $3 \mathrm{GHz}$ & End fire & 1.584 & 2.017 & \multirow{17}{*}{$\begin{array}{l}3.1 \mathrm{GHz}- \\
10.5 \mathrm{GHz}\end{array}$} \\
\hline & $3.2 \mathrm{GHz}$ & End fire & 2.023 & 2.227 & \\
\hline & $3.5 \mathrm{GHz}$ & End fire & 2.150 & 2.206 & \\
\hline & $3.8 \mathrm{GHz}$ & End fire & 2.634 & 2.845 & \\
\hline & $4 \mathrm{GHz}$ & End fire & 3.103 & 3.369 & \\
\hline & $4.5 \mathrm{GHz}$ & End fire & 3.279 & 3.546 & \\
\hline & $4.9 \mathrm{GHz}$ & End fire & 2.974 & 3.249 & \\
\hline & $5 \mathrm{GHz}$ & End fire & 2.860 & 3.124 & \\
\hline & $5.5 \mathrm{GHz}$ & End fire & 2.553 & 2.798 & \\
\hline & $5.7 \mathrm{GHz}$ & End fire & 2.655 & 2.917 & \\
\hline & $6 \mathrm{GHz}$ & End fire & 2.898 & 3.217 & \\
\hline & $6.5 \mathrm{GHz}$ & End fire & 3.288 & 3.717 & \\
\hline & $7 \mathrm{GHz}$ & End fire & 3.796 & 4.382 & \\
\hline & $7.5 \mathrm{GHz}$ & End fire & 4.938 & 5.681 & \\
\hline & $8 \mathrm{GHz}$ & End fire & 5.920 & 6.872 & \\
\hline & $8.2 \mathrm{GHz}$ & End fire & 6.292 & 7.338 & \\
\hline & $8.5 \mathrm{GHz}$ & End fire & 6.705 & 7.902 & \\
\hline
\end{tabular}




\begin{tabular}{|c|c|c|c|c|c|}
\hline & $9 \mathrm{GHz}$ & End fire & 7.005 & 8.344 & \\
\hline \multirow{16}{*}{$\begin{array}{l}\text { Proposed antipodal Vivaldi } \\
\text { antenna with slits and with } \\
\text { meandered edge }\end{array}$} & $3 \mathrm{GHz}$ & End fire & 1.557 & 2 & \multirow{16}{*}{$\begin{array}{l}2.6 \mathrm{GHz}- \\
10.4 \mathrm{GHz}\end{array}$} \\
\hline & $3.2 \mathrm{GHz}$ & End fire & 2.032 & 2.236 & \\
\hline & $3.5 \mathrm{GHz}$ & End fire & 2.212 & 2.265 & \\
\hline & $4 \mathrm{GHz}$ & End fire & 3.203 & 3.489 & \\
\hline & $4.5 \mathrm{GHz}$ & End fire & 3.375 & 3.645 & \\
\hline & $4.9 \mathrm{GHz}$ & End fire & 3.061 & 3.350 & \\
\hline & $5 \mathrm{GHz}$ & End fire & 2.946 & 3.225 & \\
\hline & $5.5 \mathrm{GHz}$ & End fire & 2.683 & 2.945 & \\
\hline & $5.7 \mathrm{GHz}$ & End fire & 2.790 & 3.077 & \\
\hline & $6 \mathrm{GHz}$ & End fire & 3.006 & 3.355 & \\
\hline & $6.5 \mathrm{GHz}$ & End fire & 3.364 & 3.813 & \\
\hline & $7 \mathrm{GHz}$ & End fire & 3.845 & 4.439 & \\
\hline & $7.5 \mathrm{GHz}$ & End fire & 4.972 & 5.753 & \\
\hline & $8 \mathrm{GHz}$ & End fire & 5.880 & 6.919 & \\
\hline & $8.5 \mathrm{GHz}$ & End fire & 6.502 & 7.812 & \\
\hline & $9 \mathrm{GHz}$ & End fire & 6.738 & 8.129 & \\
\hline
\end{tabular}

\section{III.Proposed Breast Phantom}

For detection purpose, a hemispherical breast phantom of radius $50 \mathrm{~mm}$ is built. The phantom consists of two layer tissues and tumor. The phantom is implemented and measured to have a dielectric constant similar to the real dielectric constant of real breast tissues and tumor. The breast phantom tissue is a mixture of water (39.77\%), Sugar (53.41\%) and Gelatine (6.82\%). The permittivity and conductivity of the breast phantom and tumor are measured using DAK system and Vector Network Analyzer (VNA). The results are very close to that were predicted in [17-18]. Figure 16 shows the dielectric constant curves of both tissues and tumor.

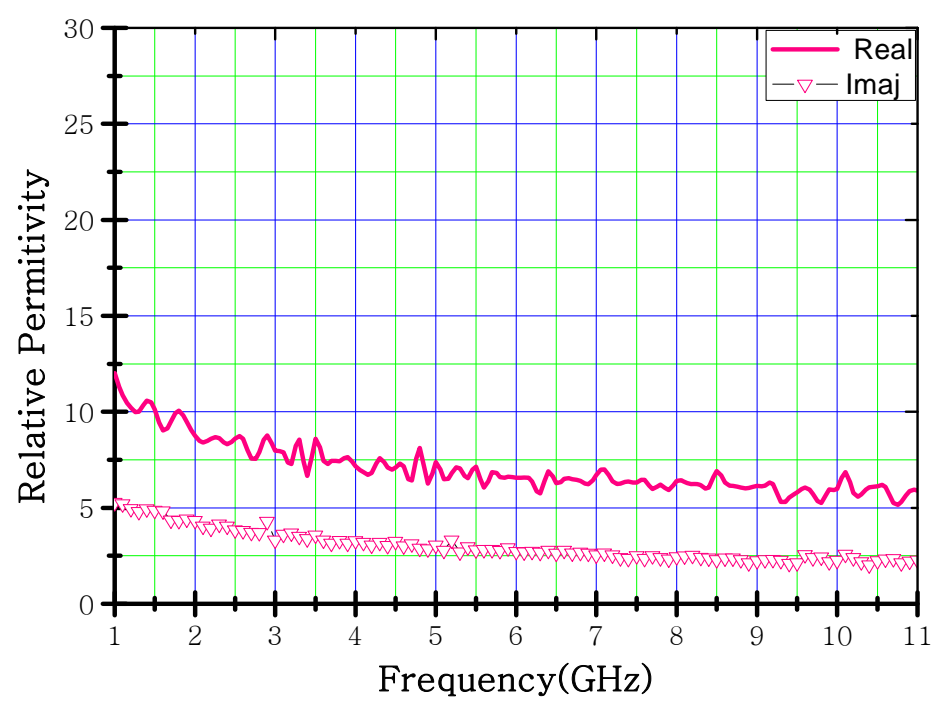

(a) 


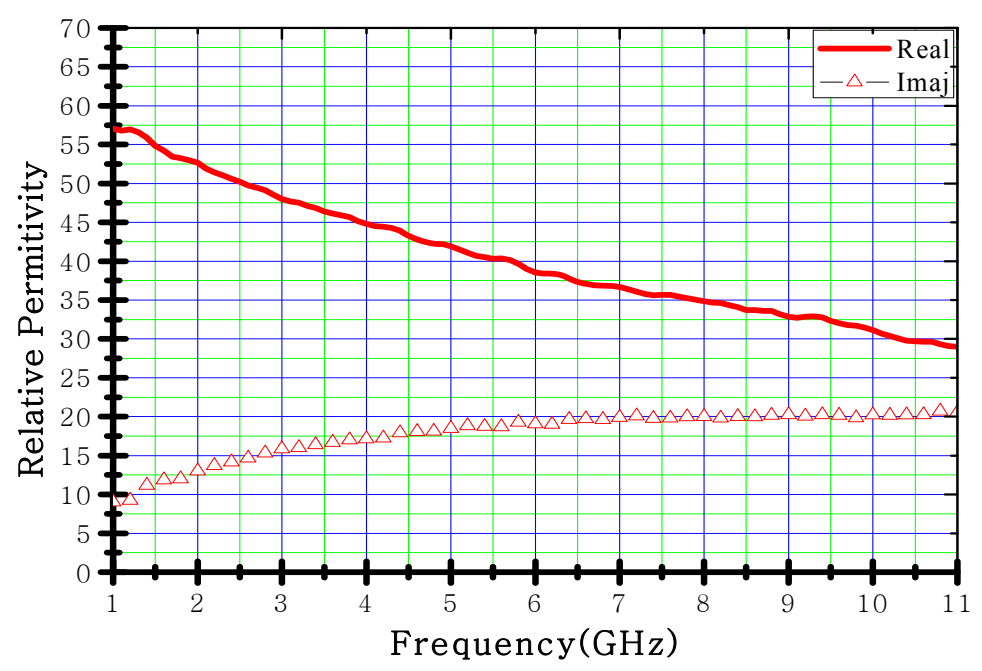

(b)

Fig. 16 The measured dielectric constant of phantom (a) Tissues (b) Tumor.

\section{IV.BREAST CANCER DETECTION USING THE PROPOSED ANTENNAS}

It had been demonstrated in [18] that one antenna pair was sufficient to classify tumors sizes in phantoms but had little success with the clinical trial. In this section, only one antenna is used to demonstrate the idea of microwave breast cancer detection. The proposed antennas with two layers phantom (tissues and tumor) are simulated. The electric field distribution inside the breast phantom with and without tumor are monitored with considering the dispersive phantom materials that were measured in Fig. 16. Figures 17 to 46 show the electric field distribution inside the two phantoms with and without tumors using the two proposed antennas. Also, these figures show that the electric field distribution changed inside the phantom especially in the tumor presence due to the high contrast between the breast tissue and tumor dielectric constant. In the tissue layer the output field from the antenna partially passed inside the tissue layer, but in tumor the field was exceedingly low due to its high permittivity and this simulation make the detection process sufficient and easy to notice the tumor position.

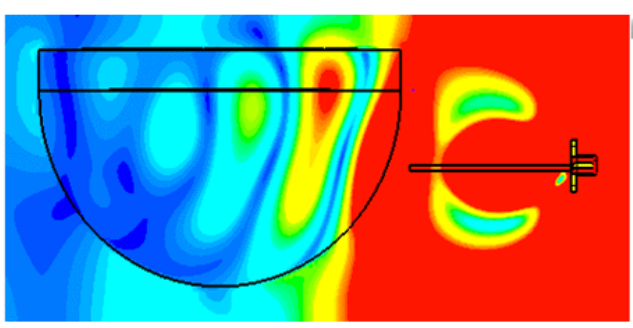

(a)

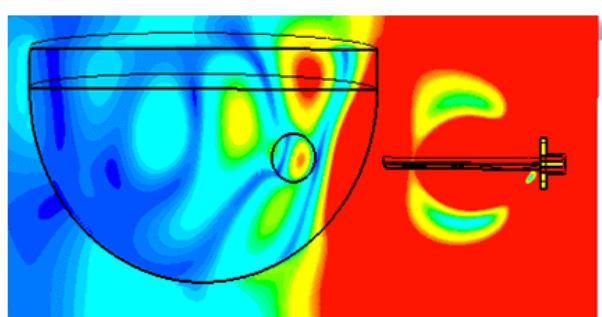

(b)

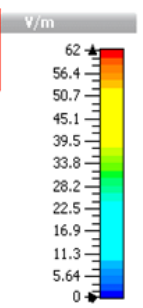

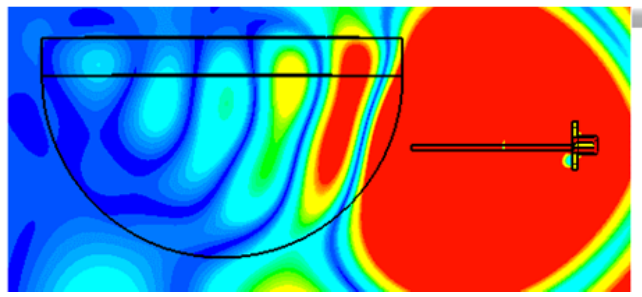

(a)
Fig. $17 \mathrm{E}$ - field distribution at $3 \mathrm{GHz}$ using AVA with slits a) without tumor b) with tumor
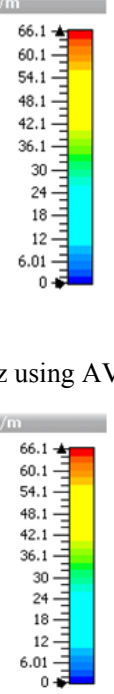

Fig. $18 \mathrm{E}$ - field distribution at $3.5 \mathrm{GHz}$ using AVA with slits a) without tumor b) with tumor

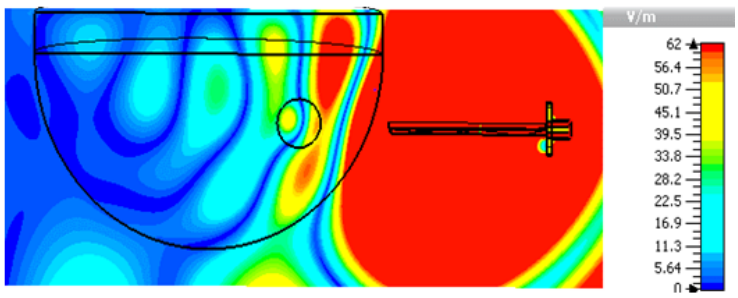

(b) 


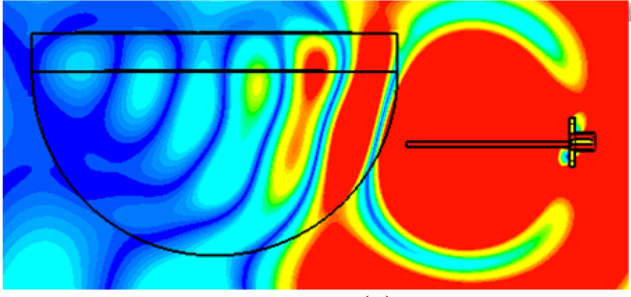

(a)

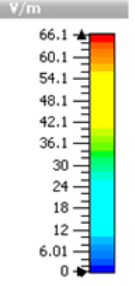

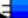

Fig. $19 \mathrm{E}$ - field distribution at $4 \mathrm{GHz}$ using AVA with slits a) without tumor b) with tumor

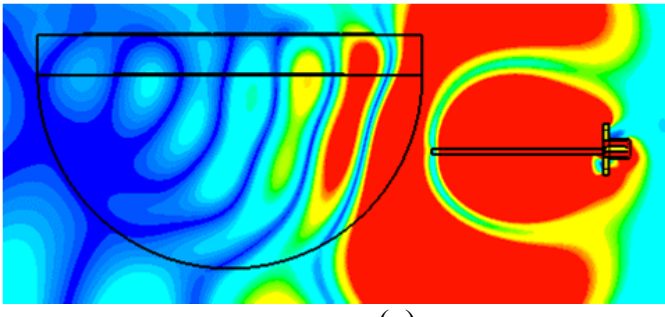

(a)

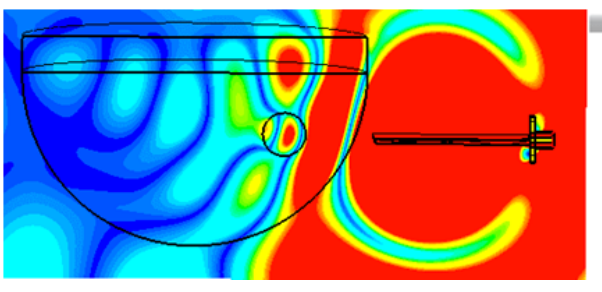

(b)

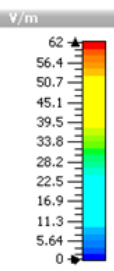

5.64

Fig. 20 E- field distribution at $4.5 \mathrm{GHz}$ using AVA with slits a) without tumor b) with tumor

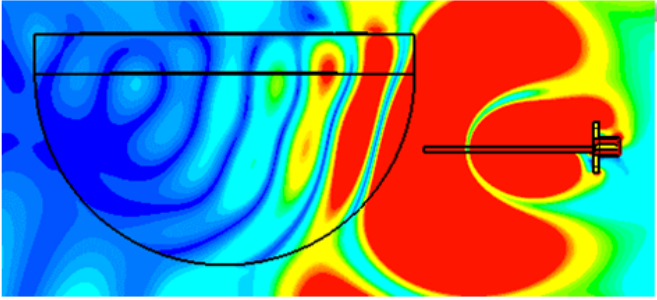

(a)

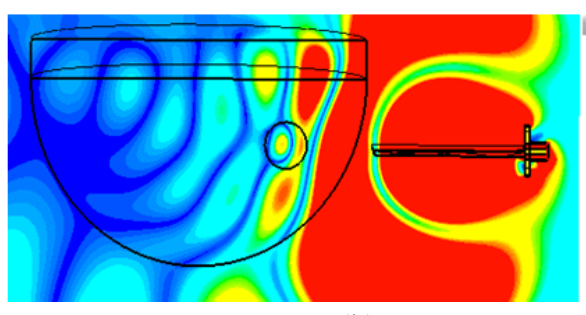

(b)
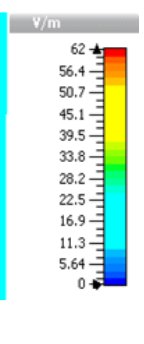

(n)




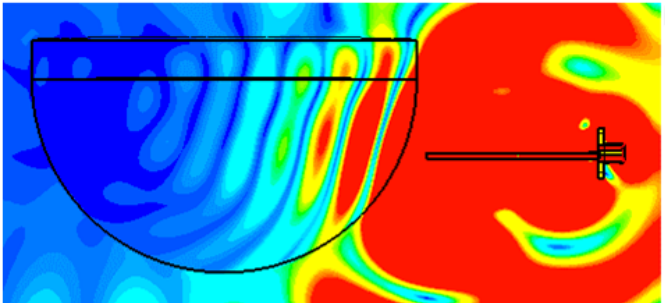

(a)

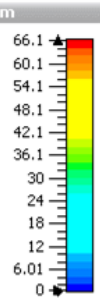

6.01

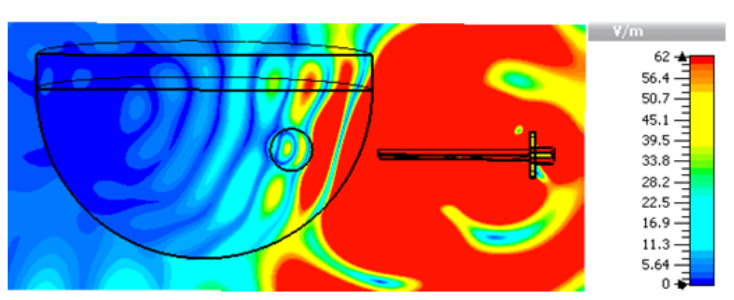

(b)

Fig. 24E- field distribution at $6.5 \mathrm{GHz}$ using AVA with slits a) without tumor b) with tumor

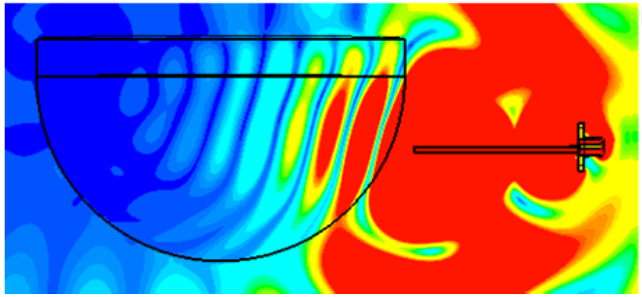

(a)

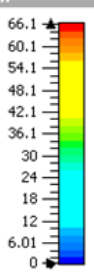

Fig. 25E- field distribution at $7 \mathrm{GHz}$ using AVA with slits a) without tumor b) with tumor

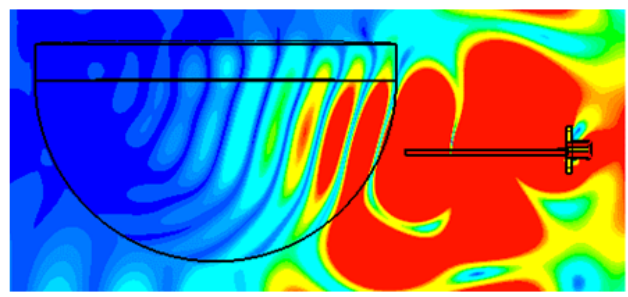

(a)

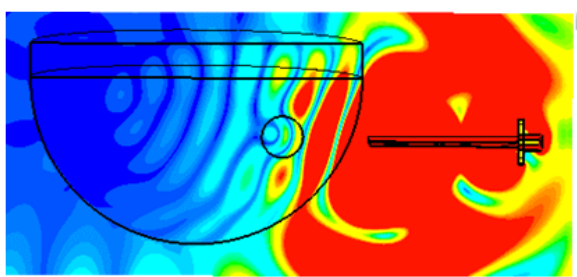

(b)

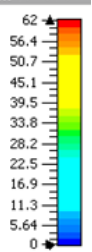

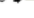




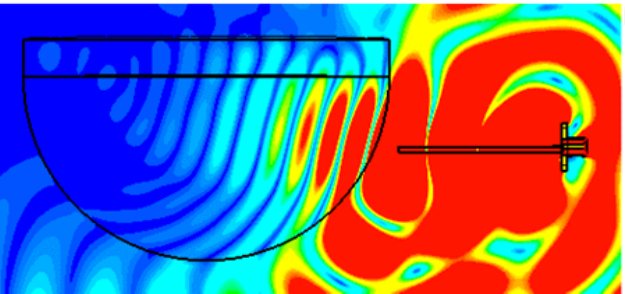

(a)

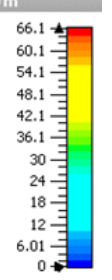

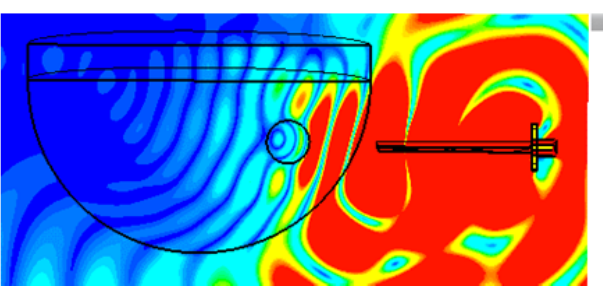

(b)

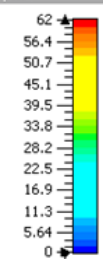

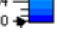

Fig. 29E- field distribution at $9 \mathrm{GHz}$ using AVA with slits a) without tumor b) with tumor

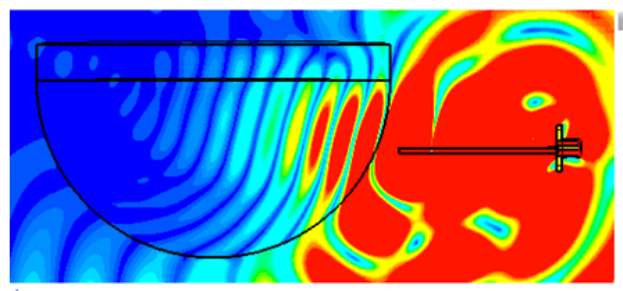

(a)

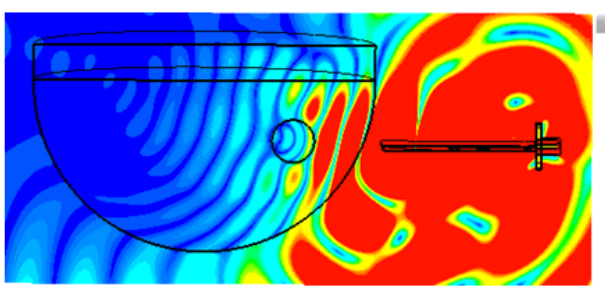

(b)

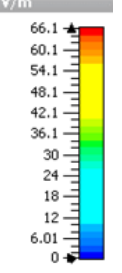

Fig. 30E- field distribution at $9.5 \mathrm{GHz}$ using AVA with slits a) without tumor b) with tumor

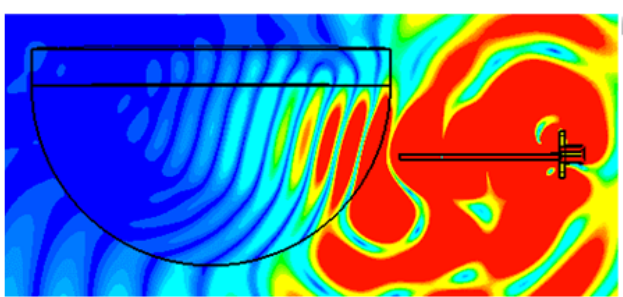

(a)

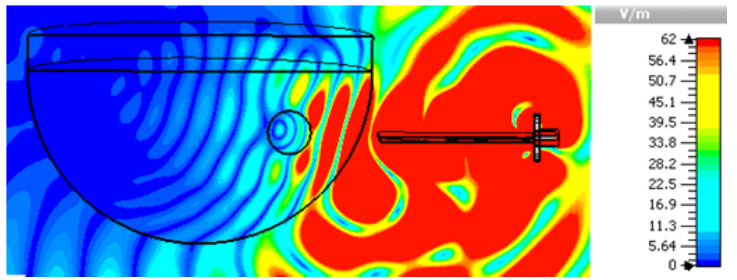

(b)

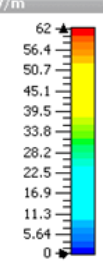

.

.

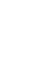




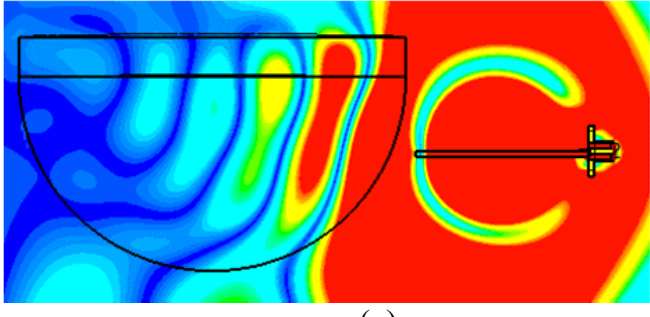

(a)

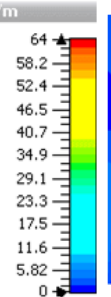

$5.82=$

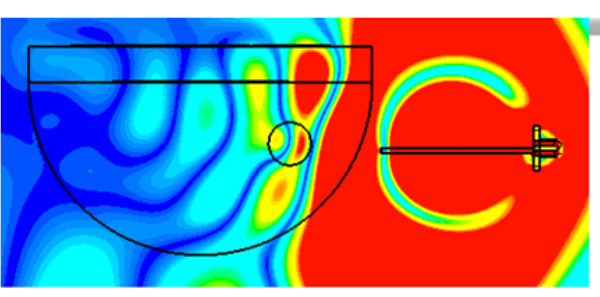

(b)

Fig. $34 \mathrm{E}$ - field distribution at $4 \mathrm{GHz}$ using AVA with slits and meandered edges a) without tumor b) with tumor

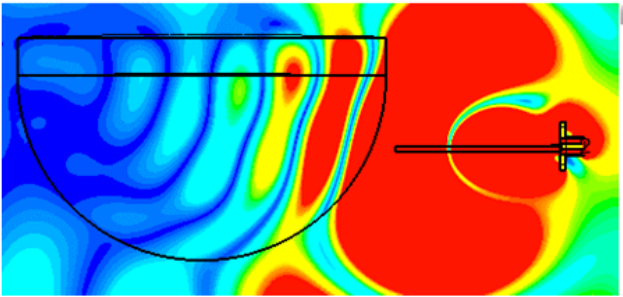

(a)

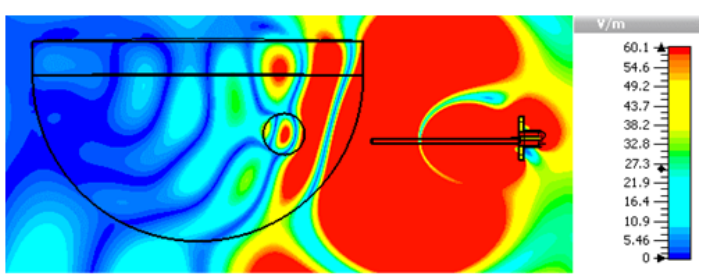

(b)

Fig. 35E- field distribution at $4.5 \mathrm{GHz}$ using AVA with slits and meandered edges a) without tumor b) with tumor

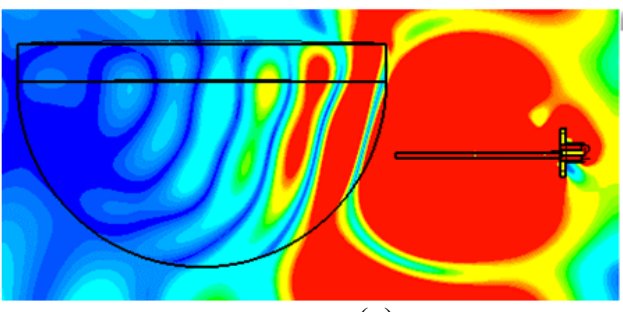

(a)

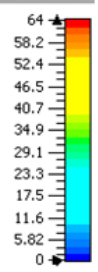

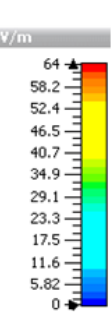

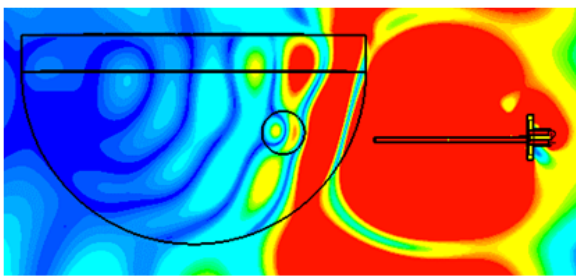

(b)

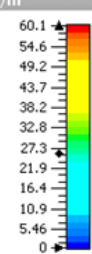

5.46

Fig. 36E- field distribution at $5 \mathrm{GHz}$ using AVA with slits and meandered edges a) without tumor b) with tumor

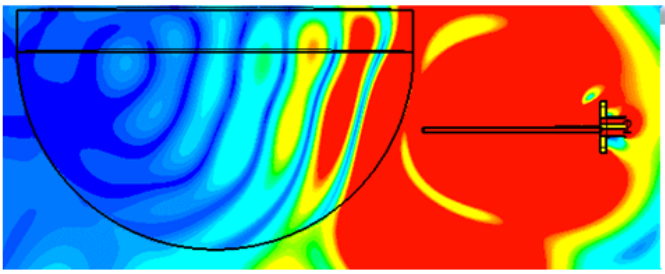

(a)

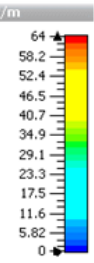

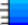

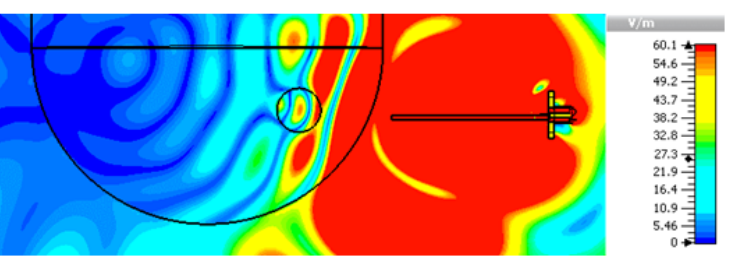

(b)

Fig. 37E- field distribution at $5.5 \mathrm{GHz}$ using AVA with slits and meandered edges a) without tumor b) with tumor

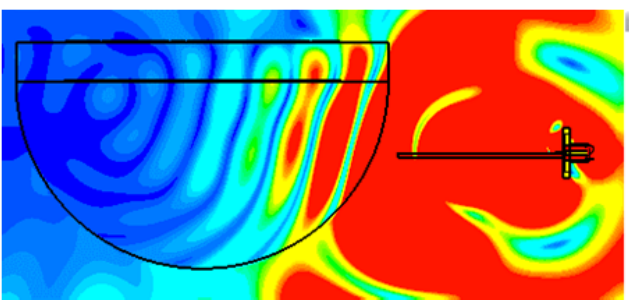

(a)

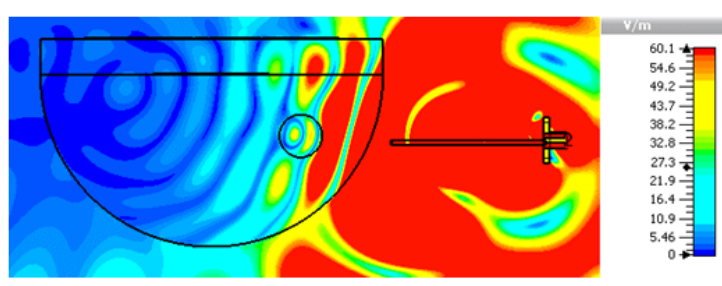

(b)

Fig. 38E- field distribution at $6 \mathrm{GHz}$ using AVA with slits and meandered edges a) without tumor b) with tumor 


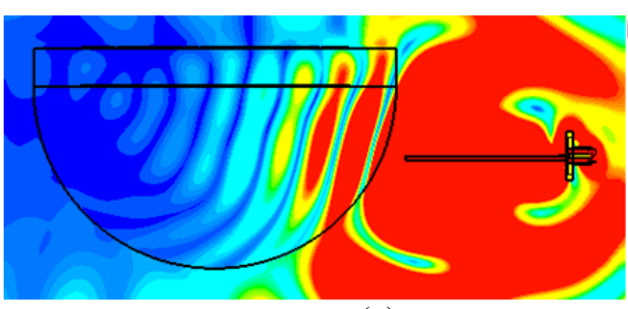

(a)

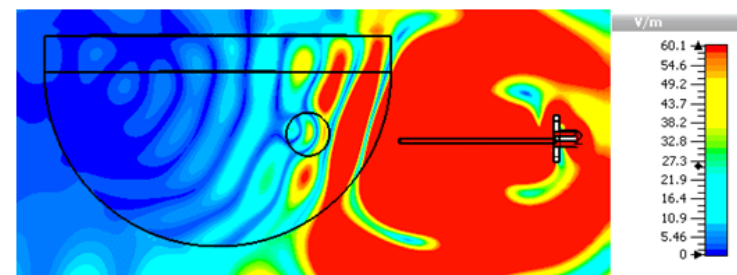

(b)

Fig. 39E- field distribution at $6.5 \mathrm{GHz}$ using AVA with slits and meandered edges a) without tumor b) with tumor

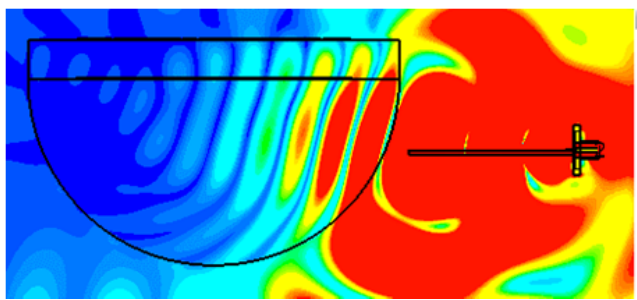

(a)

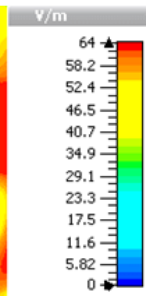

(b)

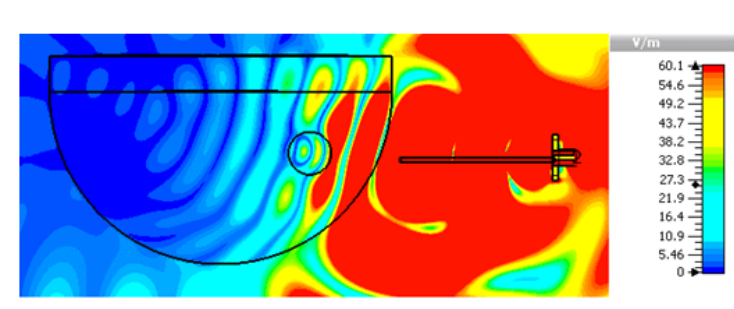

Fig. 40E- field distribution at $7 \mathrm{GHz}$ using AVA with slits and meandered edges a) without tumor b) with tumor

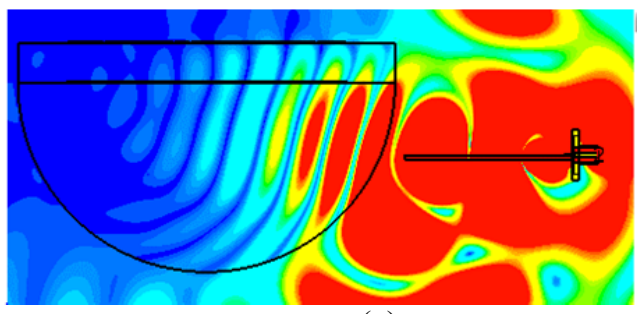

(a)

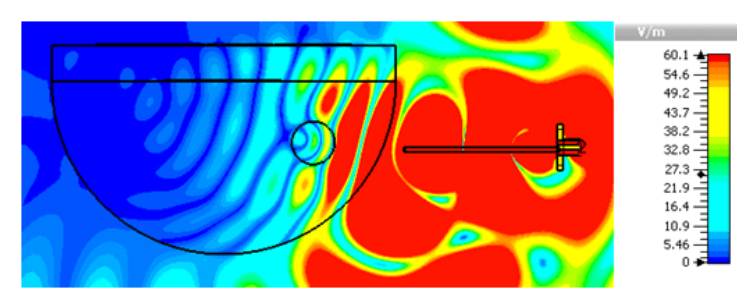

(b)

Fig. 41E- field distribution at $7.5 \mathrm{GHz}$ using AVA with slits and meandered edges a) without tumor b) with tumor

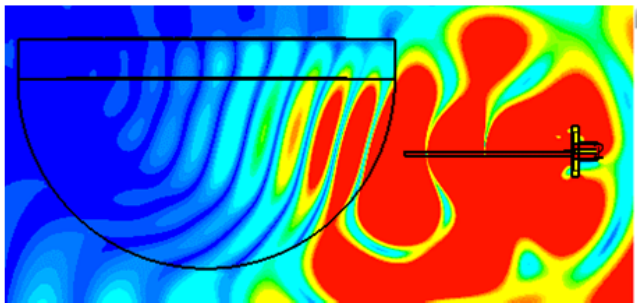

(a)

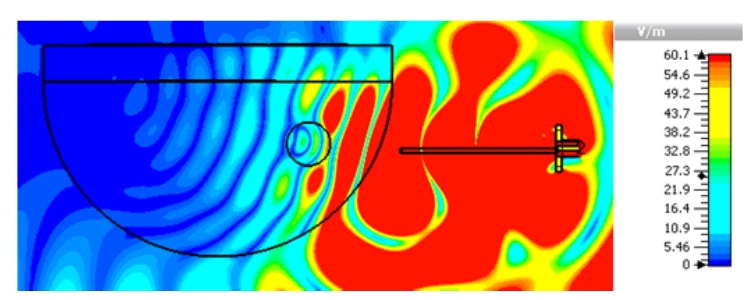

(b)

Fig. 42E- field distribution at $8 \mathrm{GHz}$ using AVA with slits and meandered edges a) without tumor b) with tumor

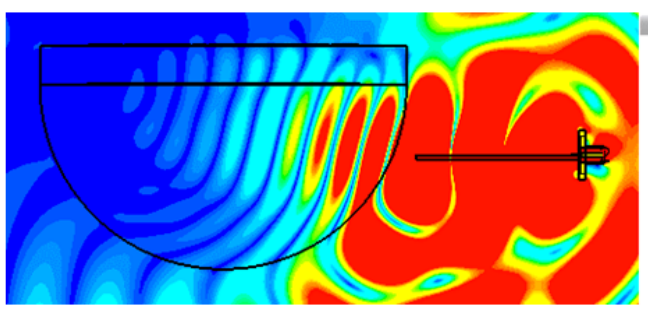

(a)

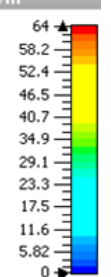

$0.82=$

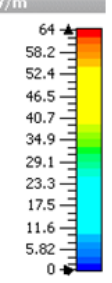
录

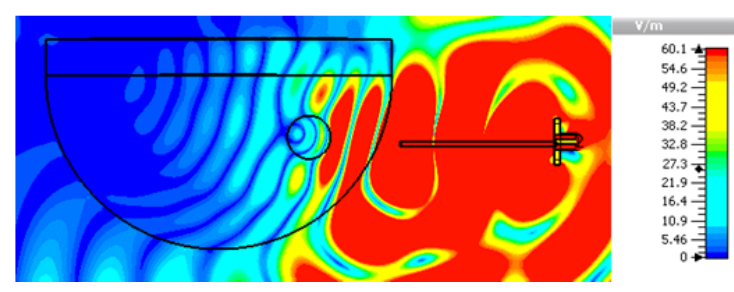

(b)

Fig. 43E- field distribution at $8.5 \mathrm{GHz}$ using AVA with slits and meandered edges a) without tumor b) with tumor 


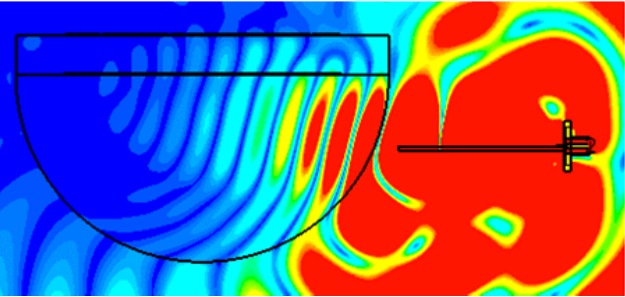

(a)

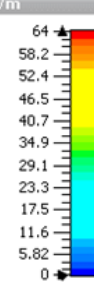

$\exists$

Fig. 44E- field distribution at $9 \mathrm{GHz}$ using AVA with slits and meandered edges a) without tumor b) with tumor

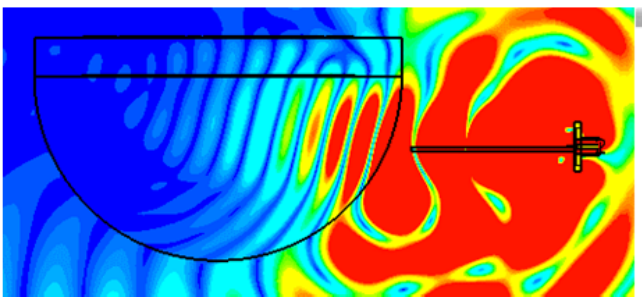

(a)

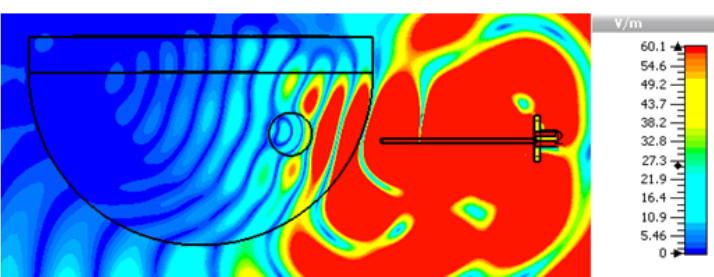

(b)

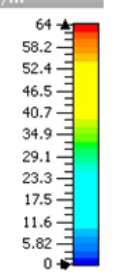

5.827

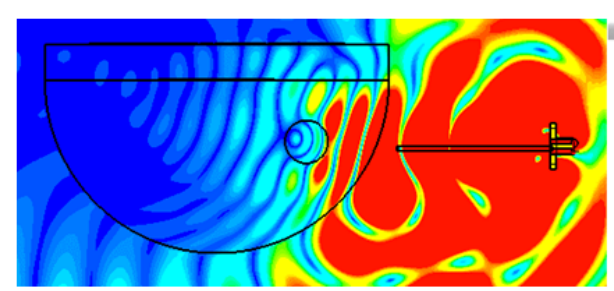

(b)

Fig. 45E- field distribution at $9.5 \mathrm{GHz}$ using AVA with slits and meandered edges a) without tumor b) with tumor

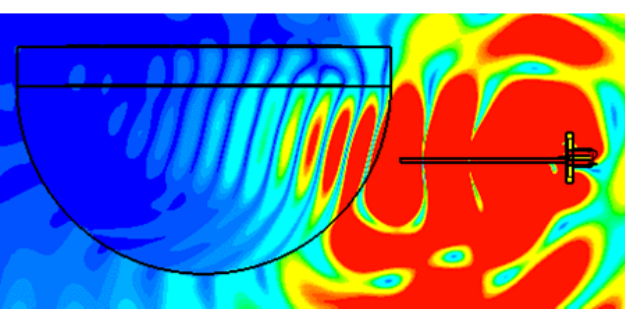

(a)

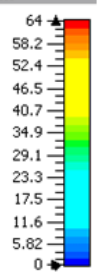

Fig. 46E- field distribution at $10 \mathrm{GHz}$ using AVA with slits and meandered edges a) without tumor b) with tumor

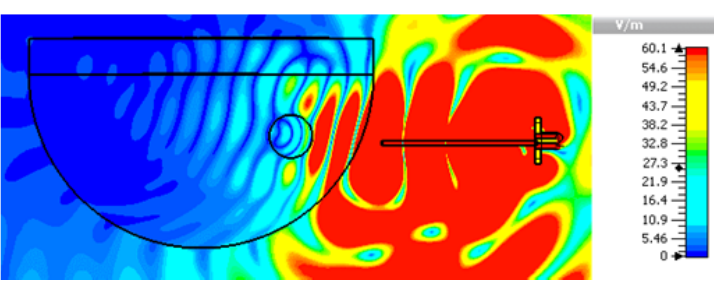

(b)

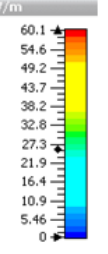

\section{CONCLUSIONS}

In this paper the idea of microwave breast cancer detection using UWB antenna was demonstrated. Vivaldi antipodal antenna was considered as a basic structure due to its well-known UWB characteristics. For bandwidth enhancement the feeding line was modified and an UWB performance was obtained. The problem arose from the broadside radiation pattern at the lower frequency band. This problem was solved by adding slits at the antenna's edge. The proposed antennas bandwidth extended from $2.6 \mathrm{GHz}$ to $11.6 \mathrm{GHz}$. Also, two breast phantoms with and without tumor were considered. The fields' distribution inside the phantom with and without tumor were investigated. The proposed antennas were fabricated and measured. Good agreement was obtained between simulated and measured results.

\section{REFERENCES}

[1] E. C.Fear, P. M. Meaney, and M. A. Stuchly, "Microwaves for breast cancer detection," IEEE potentials, vol. 22, no. 1,pp. 12-18, 2003.

[2] R. Nilavalan, I.J. Craddock, A. Preece, J. Leendertz and R. Benjamin, "Wideband microstrip patch antenna design for breast cancer tumour detection," IET Microwaves, Antennas and Propagation, vol. 1, pp. 277 - 281, 2007.

[3] S.C.Hagness, A.Tafove, andJ.E.Bridges, "Two-dimensional FDTD analysis of a pulsed microwave confocal system for breast cancer detection fixed-focus and antenna-array sensors,"IEEE Transaction Biomedical Engineering, vol. 45, pp. 1470-1479, 1998.

[4] E.C.Fear, and M.A.Stuchly, "Microwave detection of breast cancer,"IEEE Trans. Microwave Theory Tech., vol. 48, pp. 1854-1863, 2000.

[5] M.Klemm, I. J. Craddock,J. A. Leendertz,A. Preece, andR.Benjamin,"Radar based breast cancer detection using a hemispherical antenna array-experimental results", IEEE Transactions on Antennas and Propagation, vol. 57, pp. $1692-1704,2009$.

[6] D. Gibbins, M. Klemm, I. J. Craddock, J. A. Leendertz, A. Preece, and R. Benjamin, "a comparison of a wide-slits and a stacked patch antenna for the purpose of breast cancer detection", IEEE Transactions on Antennas and Propagation, vol. 58, pp. $665-674,2010$.

[7] J. Bourqui, M. Okoniewski, and E. C. Fear, "Balanced antipodal Vivaldi antenna with dielectric director for near field microwave imaging," IEEE Transactions on Antennas and Propagation, vol. 58, pp. $2318-2326,2010$.

[8] M. A. Al-Joumayly, S. M. Aguilar, N. Behdad, and S. C. Hagness, "Dual-band miniaturized patch antennas for microwave breast imaging", IEEE Antennas and Wireless Propagation Letters, vol. 9, pp. 268 - 271, 2010.

[9] L. Xuyang, J. Malyhe,L. Yoke, and Z. Thomas, “ A Compact double-layer on-body matched bowtie antenna for medical diagnosis", IEEE Transactions on Antennas and Propagation, vol. 62, pp. 1808 - 1816, 2014.

[10] M. H. Bah, J. Hong, D. A. Jamro, J. J. Liang, and E. A. Kponou, "Vivaldi antenna and breast phantom design for breast cancer imaging", 7th International Conference on Biomedical Engineering and Informatics, pp. 90 - 93, 2014. 
[11] J. Malyhe, L. Zwirello, and Z. Thomas, “ Ultra wideband compact near-field imaging system for breast cancer detection”, IET Microwaves, Antennas and Propagation,vol. 9, pp.1009-1014, 2015.

[12] H. Bahrami, E. $\quad$ Porter, A. $\quad$ Santorelli, B. Gosselin, M. $\quad$ Popovic, L. A. Rusch, "Flexible sixteen monopole antenna array for microwave breast cancer detection", 36th Annual International Conference of the IEEE Engineering in Medicine and Biology Society, pp. 3775 - 3778, 2014.

[13] A. M. Abbosh, H. K. Kan, and M. E. Bialkowski, "Compact ultra-wideband planar tapered slot antenna for use in a microwave imaging system," Microwave and Optical Technology Letters, vol. 48, pp. 2212-2216, 2006.

[14] A. Abbosh, "Directive antenna for ultra-wideband medical imaging systems," International Journal of Antennas and Propagation, 2008.

[15] D. M. Pozar, Microwave Engineering, 4th ed., John Wiley \& Sons, USA, 2011.

[16] K. Kumar, and N. Gunasekaran, "A novel wideband slotted mm wave microstrip patch antenna,"IEEE Signal Processing, Communication, Computing and Networking Technologies (ICSCCN), pp.10 - 14, 2011.

[17] M. Lazebnik, D. Popovic, and L. McCartney, "A large-scale study of the ultrawideband microwave dielectric properties of normal, benign and malignant breast tissues obtained from cancer surgeries," Physics in Medicine and Biology, vol. 52, pp. 6093-6115, 2007.

[18] K. Nagmani, V. Mishra, P. Smitha, D. Singh, K. P. Singh, and N. S. Rajput, "Development of electromagnetic approach for early breast tumor detection," IEEE International Geoscience and Remote Sensing Symposium (IGARSS), pp. 724-727, 2016.

[19] L. Yunpeng, A. Santorelli, and M. Coates, "Comparison of microwave breast cancer detection results with breast phantom data and clinical trial data, varying the number of antennas," IEEE 10th European Conference on Antennas and Propagation (EuCAP), pp. 1-5, 2016.

\section{AUTHOR PROFILE}

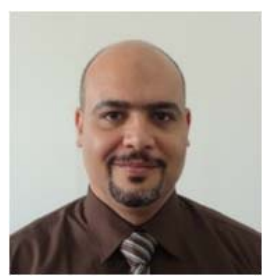

Tamer Abouelnaga was born in 1976. He received his B.Sc. degree in Electronics Engineering from Menofia University, Egypt in May 1999. He received his M.Sc. and $\mathrm{Ph}$. D. degrees in Electrical and Communication Engineering from Ain Shams University, Egypt in 2007 and 2012, respectively. His master's thesis was about the design of dielectric resonator antenna for S-band application and the Ph.D. thesis was about the RFID antennas design and analysis. From 2001 to 2007, he was a Researcher Assistant. From 2007 to 2012, he was an Assistant Researcher. From 2012 till now he is a Researcher in the Microstrip Department, Electronics Research Institute, Giza, Egypt.

Also he worked as an Assistant Professor in the Higher Institute of Engineering and Technology, Kafr ElShiekh in the period from 2015 to 2017 and as Assistant Professor in the American University in Cairo in the period of 2012 to 2015 . He has published 15 papers in peer-refereed journals and 8 papers in international conferences in the area of the microstrip circuits' components, RFID and DRA antenna design. His research interests includes antennas, microstrip circuit components and RFID system components. His current research interest on the biomedical area especially on the microwave breast cancer detection and therapy.

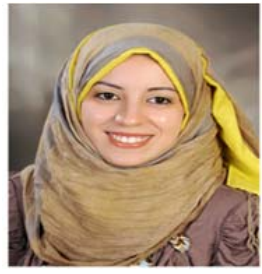

Asmaa Desouky is a Post Graduate Student (master), Alexandria University, Egypt. She was born in Kafr El-Shiekh, Egypt. She received her B.Sc. degree in Electronics and Communication Engineering from HIET, Kafr El-Shiekh, Egypt in May 2011.She is a demonstrator at Higher Institute of Engineering and Technology (HIET) in Kafr El-Shiekh, Egypt in the period from 2011 to 2016.Her current research interest is biomedical Engineering area especially on the microwave breast cancer detection and Treatment. 